\title{
Bilateral ocular ischemia-induced blindness as a presenting manifestation of Takayasu arteritis: a case report
}

\author{
Pedro Pallangyo ${ }^{1 *}$, Emmanuel Epafra ${ }^{1}$, Paulina Nicholaus ${ }^{1}$, Frederick Lyimo² ${ }^{2}$ Parvina Kazahura ${ }^{1}$ \\ and Mohamed Janabi ${ }^{1}$
}

\begin{abstract}
Background: Takayasu arteritis is a granulomatous panarteritis that predominantly affects the aorta and its major branches. The initial manifestations of this large-vessel vasculitis are usually nonspecific; however, as the disease progresses, typical symptoms of arterial occlusion, aneurysmal formation, and vascular pain become evident. Ischemic ocular complications of Takayasu arteritis which could lead to complete loss of vision are not uncommon and depend on the obliterated portion(s) of carotid(s), the intensity and rate of progression of ocular vascular insufficiency, and sufficiency of the collateral blood supply to the eye.
\end{abstract}

Case presentation: A 24-year-old woman of African descent with prior normal vision was referred to us with a 3-year history of gradual decline in visual acuity in both eyes and unintentional weight loss $(17 \mathrm{~kg})$ within the past 1 year. A physical examination revealed feeble brachial and radial arterial pulses on her left side. She had sinus tachycardia (136 beats/minute) and her blood pressure was $85 / 59 \mathrm{mmHg}$ on her left and 134/82 $\mathrm{mmHg}$ on her right side. Bilateral microaneurysms, dot and blot hemorrhages, and multiple ischemic areas of retina together with neovascularization in her right eye were noted during a funduscopic examination. Computed tomography angiography of her thoracic and abdominal aorta revealed irregular narrowing with variable degrees of stenosis, tapering, and corrugated appearance.

Conclusions: Despite its rarity, Takayasu arteritis significantly impairs a patient's quality of life and has a life-threatening potential. Early initiation of appropriate therapy could delay disease progression and reduce the associated complications.

Keywords: Takayasu arteritis, Occlusive thromboaortopathy, Granulomatous panarteritis, Chronic granulomatous vasculitis, Large vessel vasculitis, Pulseless disease, Case report

\section{Background}

Takayasu arteritis (TA) is a rare, idiopathic, autoimmune, and progressive chronic granulomatous vasculitis that is largely $(90 \%)$ seen in young women ( $<40$ years) [1-7]. This nonspecific aortoarteritis predominantly affects the aorta and its major branches; however, coronary, renal, and pulmonary arteries involvement has been documented [1-3]. The diffuse nature of TA leads to multiorgan system involvement with varying degrees of pathological features including

\footnotetext{
* Correspondence: pedro.pallangyo@gmail.com

${ }^{1}$ Department of Cardiovascular Medicine, Jakaya Kikwete Cardiac Institute,

P.O. Box 65141, Dar es Salaam, Tanzania

Full list of author information is available at the end of the article
}

thickening, fibrosis, stenosis, aneurysm, and thrombus formation in involved portions of arteries [3, 8, 9].

The initial stage (pre-vasculitic phase) of TA lacks a diagnostic test as it manifests with nonspecific symptoms including malaise, fever, headache, arthralgias, and weight loss [10-12]. During the late stage (pulseless phase), symptoms of arterial occlusion, aneurysmal formation, and vascular pain (carotidynia) are evident and patients present with a myriad of clinical syndromes like pulseless extremities, claudication, vascular bruits, hypertension, Raynaud's syndrome, pericarditis, aortic regurgitation, congestive heart failure, stroke, and myocardial infarction [10-12]. Erythema nodosum is the commonest dermatologic manifestation of $\mathrm{TA}$; other 
dermatologic manifestations, including ulcerated subacute nodular lesions and pyoderma gangrenosum, occur less frequently $[11,12]$. Neurological manifestations including seizures, syncope, blindness, and stroke are not uncommon and may be the initial presentation of the disease $[8,11-13]$. We report a case of blindness as the initial presentation of TA in a 24-year-old woman from Tanzania.

\section{Case presentation}

A 24-year-old woman of African descent with prior normal vision was referred to us from a specialized ophthalmic center for a preoperative cardiovascular assessment. She had chief complaints of gradual decline in visual acuity in both eyes for 3 years and unintentional weight loss $(17 \mathrm{~kg})$ within the past 1 year. Her past medical history was unremarkable except for a self-reported history of pulmonary tuberculosis at the age of 4 years. Her progressive loss of vision which initially started in her left eye and later involved her right eye was associated with intermittent pain, redness, tearing, and headaches. Within the first year, she completely lost vision in her left eye. She denied any history of arthralgias, claudication, skin lesions, chest pain, convulsions, or syncope. She had several out-patient visits in the past 3 years all due to her ongoing visual impairment. She was prescribed gentamycin eye drops, carbimazole, propranolol, furosemide, and multivitamin capsules at different points in time with no relief of her deteriorating vision.

Her physical examination revealed feeble brachial and radial arterial pulses on her left side, whereas pulses on her right side and in both lower limbs were normal. Her blood pressure was $85 / 59 \mathrm{mmHg}$ on her left and $134 / 82 \mathrm{mmHg}$ on her right side. She had a pulse rate of 136 beats/minute which was regular and of good volume, body temperature of $37.0{ }^{\circ} \mathrm{C}$, and a body mass index (BMI) of $19.6 \mathrm{~kg} / \mathrm{m}^{2}$. On ophthalmic examination, she had no light perception in her left eye but she could count fingers at a 2-meter distance using her right eye. Bilateral microaneurysms, dot and blot hemorrhages, and multiple ischemic areas of retina together with neovascularization in her right eye were noted during a funduscopic examination. These ophthalmic findings are in line with a bilateral ocular ischemic syndrome.

Laboratory results revealed an elevated erythrocyte sedimentation rate (ESR) and C-reactive protein (CRP) of $56 \mathrm{~mm} /$ hour and $25.4 \mathrm{mg} / \mathrm{L}$ respectively. Electrolytes, liver, renal, and thyroid function tests were normal. Serology for human immunodeficiency virus (HIV), hepatitis B and C, Venereal Disease Research Laboratory (VDRL) test for syphilis, rheumatoid factor, anti-doublestranded DNA (dsDNA), and antineutrophil cytoplasmic antibody (ANCA) were negative, however, antinuclear antibody (ANA) was positive. A tuberculin test was negative. There were no aneurysmal formations, bruits, ventricular hypertrophy, or any other cardiac abnormalities apart from a sinus tachycardia and trace aortic regurgitation. We did not perform coronary angiography or computed tomography (CT) angiography of her head and neck due to her financial constraints. A CT angiogram of her thoracic and abdominal aorta revealed irregular narrowing with variable degrees of stenosis, tapering, and corrugated appearance (Figs. 1, 2, and 3). Based on the clinical presentation, physical findings, and angiographic features, she fulfilled the American College of Rheumatology criteria [8] for Takayasu's arteritis. However, we could not rule out temporal arteritis in this case as our patient refused a temporal artery biopsy procedure. Nevertheless, based on the age of onset (that is, $<40$ years) and the clinicoradiographic picture (decreased pulsation of brachial artery, difference of over $10 \mathrm{mmHg}$

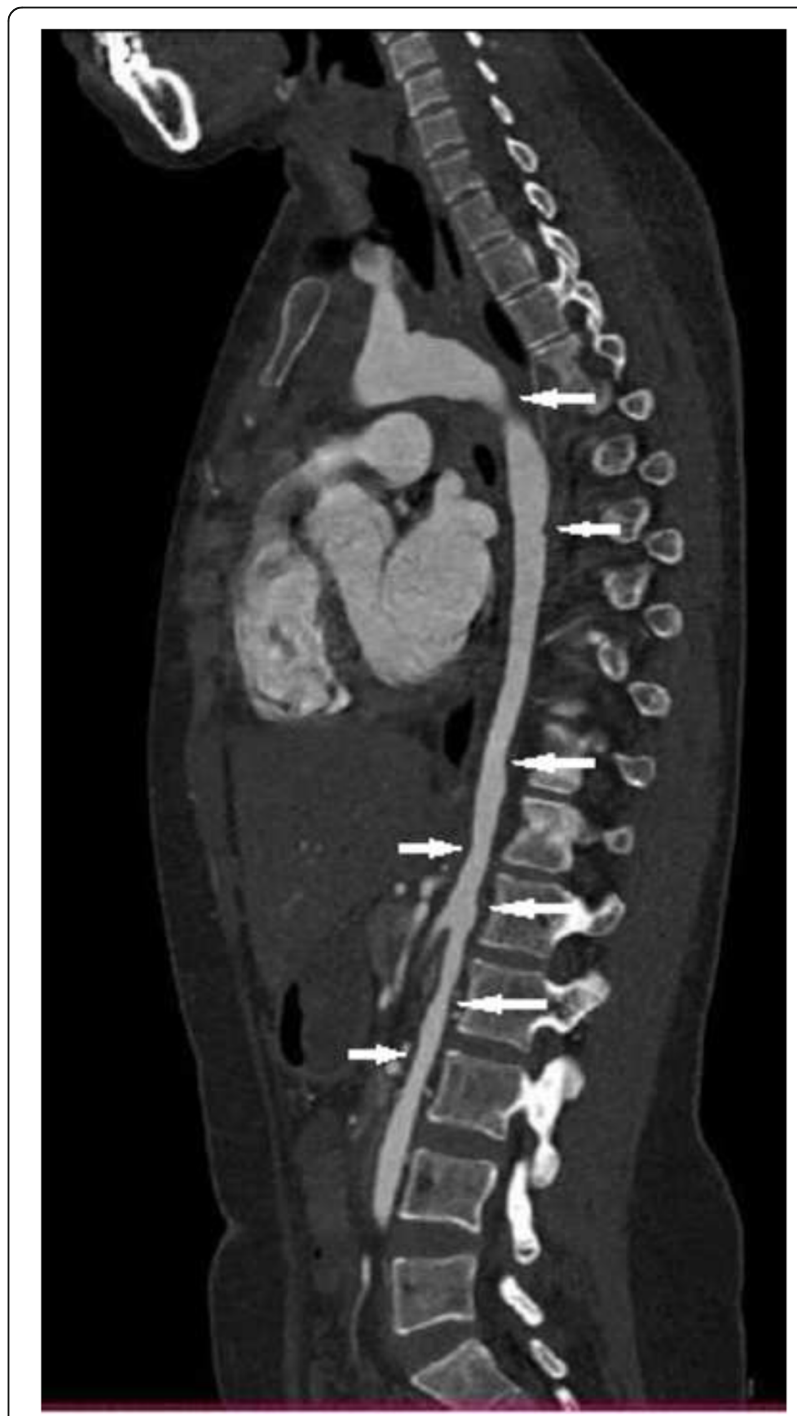

Fig. 1 Computed tomography angiography of the thoracic and abdominal aorta showing irregular narrowing with variable degrees of stenosis (arrows) and tapering 


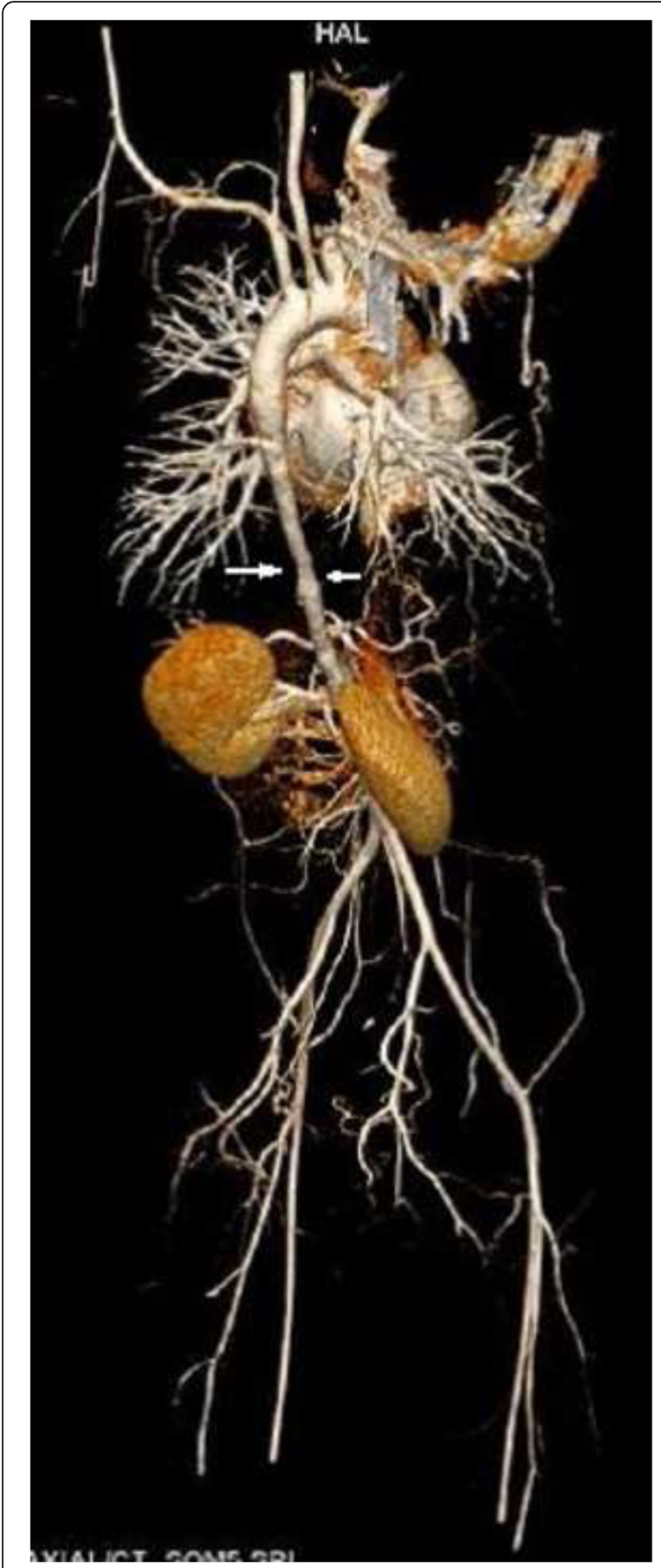

Fig. 2 Three-dimensional computed tomography scan of the thoracic and abdominal aorta showing irregular narrowing with variable degrees of stenosis (arrows), tapering and corrugated appearance

in systolic blood pressure between arms, and arteriographic narrowing of aorta) we entertained a diagnosis of TA. She was counseled and treated with dexamethasone $(60 \mathrm{mg}$ per day), methotrexate (10 mg per day), and low-dose aspirin

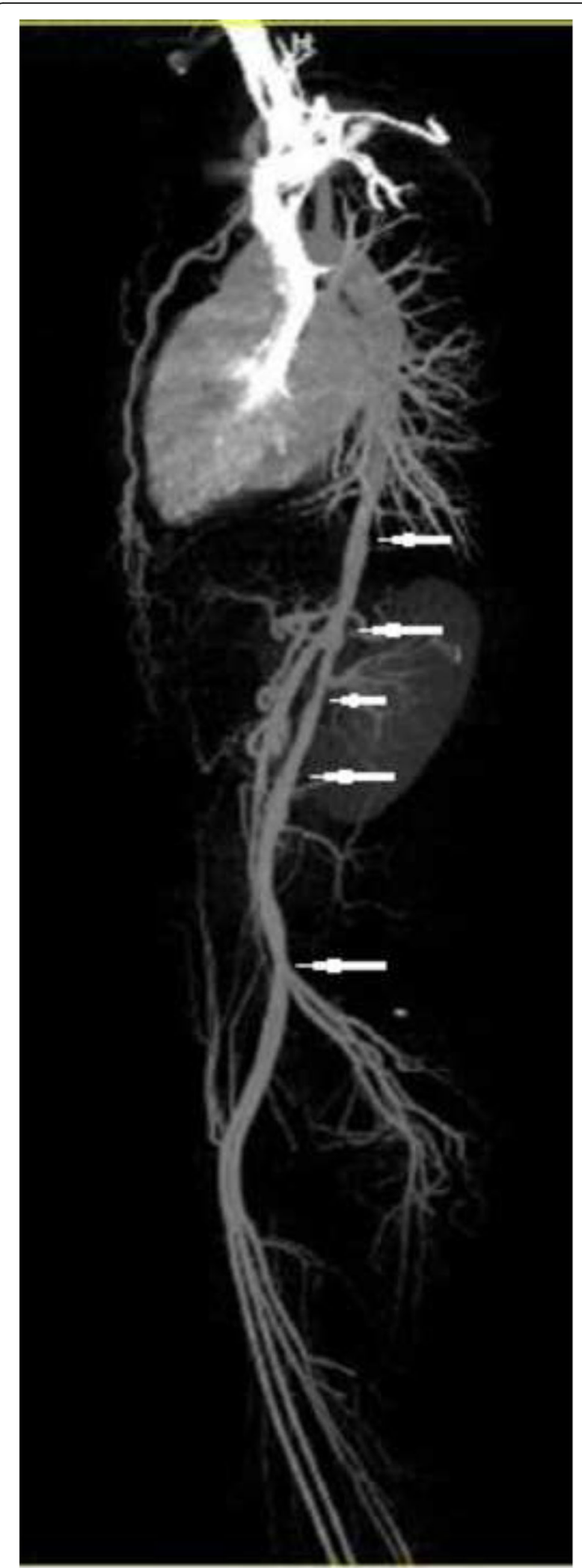

Fig. 3 Computed tomography angiography of the thoracic and abdominal aorta showing irregular narrowing with variable degrees of stenosis (arrows), tapering and corrugated appearance 
(75 mg once daily). She was discharged home on selfrequest after 9 days of hospitalization. We reviewed her as an out-patient after 3 months but there was neither improvement nor further deterioration in her visual acuity despite self-reported good adherence.

\section{Discussion}

TA is a nonspecific granulomatous polyarteritis with a poorly understood pathogenesis. This systemic vasculopathy has a variable course ranging from a rapid progression in some patients to a late quiescent phase in others [14]. In up to $90 \%$ of cases there is involvement of the aorta, subclavian arteries, and carotid arteries, and angiographic features including stenosis, occlusion, dilatation, or aneurysm are pathognomonic [3, 15]. Diagnosis of TA is a challenge to practitioners worldwide largely due to its nonspecific presentation, multiorgan system involvement, and lack of diagnostic serologic tests. For instance, ESR elevation is a common finding but nearly half of patients with active disease have a normal sedimentation rate [13]. The presence of at least three of six characteristics according to the American College of Rheumatology criteria for TA is diagnostic [13]. In the case presented, four criteria including age $\leq 40$ years, decreased brachial artery pulse, greater than $10 \mathrm{mmHg}$ difference in systolic blood pressure between arms, and arteriographic evidence of narrowing of the aorta were present.

Management of TA aims at suppressing the inflammatory process and preservation of vascular capability. Corticosteroids (that is, prednisolone) and methotrexate are a commonly used anti-inflammatory therapy while the addition of low-dose aspirin is also advocated. Approximately $20 \%$ of patients with TA are resistant to any therapy and despite good adherence to immunosuppressive medications, remission occurs only in approximately half of cases [13]. Endovascular revascularization procedures including stent placement, bypass grafts, endarterectomy, and angioplasty should be considered in patients with symptomatic stenosis or occlusion [1]. Although such surgical and endovascular interventions have a potential for short-term benefits, failure and poorer outcomes, especially when they are undertaken during active inflammatory phase, are often reported [1]. Overall, the prognosis of TA is good with reported 5-year survival rates of $90 \%$ [13-15].

The diagnosis of TA in the case presented was reached after ocular ischemia-induced blindness had set in. Ocular ischemic syndrome is a hypoperfusive retinopathy resulting from chronic hypoperfusion of the ophthalmic artery secondary to carotid artery stenosis [16-20]. The ischemic ocular complications of TA which could lead to complete loss of vision depend on the obliterated portion(s) of carotid(s), the intensity and rate of progression of ocular vascular insufficiency, and sufficiency of the collateral blood supply to the eye [18]. This case demonstrates the enigmatic character of TA and echoes the importance of a high index of suspicion for early diagnosis.

\section{Conclusions}

In conclusion, despite its rarity, TA significantly impairs a patient's quality of life and has a life-threatening potential. Early initiation of appropriate therapy could delay disease progression and reduce the associated complications.

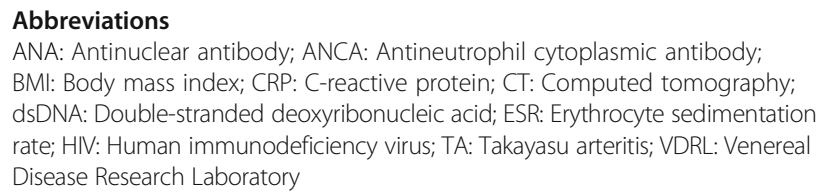

\section{Acknowledgements}

The authors are grateful to the staff of the Jakaya Kikwete Cardiac Institute and the Muhimbili National Hospital Radiology Department.

\section{Funding}

Not applicable.

\section{Availability of data and materials}

Not applicable.

\section{Authors' contributions}

PP and PN took the history and performed the physical examination. FL interpreted the $C T$ angiograms. PP wrote the initial draft of the manuscript. All authors reviewed and contributed to the final version of this case report.

\section{Competing interests}

The authors declare that they have no competing interests.

\section{Consent for publication}

Written informed consent was obtained from the patient for publication of this case report and any accompanying images. A copy of the written consent is available for review by the Editor-in-Chief of this journal.

Ethics approval and consent to participate

Ethical clearance was sought from the Directorate of Research of the Jakaya Kikwete Cardiac Institute.

\section{Publisher's Note}

Springer Nature remains neutral with regard to jurisdictional claims in published maps and institutional affiliations.

\section{Author details}

'Department of Cardiovascular Medicine, Jakaya Kikwete Cardiac Institute, P.O. Box 65141, Dar es Salaam, Tanzania. ${ }^{2}$ Department of Radiology, Muhimbili National Hospital, P.O. Box 65000, Dar es Salaam, Tanzania.

Received: 18 August 2016 Accepted: 23 May 2017

Published online: 10 June 2017

\section{References}

1. Khan MAM, Banoo H. A Case Report of Takayasu's Arteritis. Medicine Today. 2012;24(2):79-81.

2. Gao S, Wang R. Takayasu arteritis presenting with massive cerebral ischemic infarction in a 35-year-old woman: a case report. J Med Case Rep. 2013;7:179.

3. Yadav P, Prakash P, Srivastava D, Sharma SC, Matthews SE. Takayasu's Arteritis - An Unusual Presentation. JIACM. 2007;8(2):185-7.

4. Lupi-Herrera E, Sánchez-Torres G, Marcushamer J, et al. Takayasu's arteritis. Clinical study of 107 cases. Am Heart J. 1977:93:94.

5. Dabaque J, Reyes PA. Takayasu arteritis in Mexico: a 38-year clinical perspective through literature review. Int I Cardiol. 1996;54:S103. 
6. Hall S, Barr W, Lie JT, et al. Takayasu arteritis. A study of 32 North American patients. Medicine (Baltimore). 1985;64.

7. Ishikawa K. Natural history and classification of occlusive thromboaortopathy (Takayasu's disease). Circulation. 1978:57:27.

8. Vidhate M, Garg RK, Yadav R, Kohli N, Naphade P, Anuradha HK. An unusual case of Takayasu's arteritis: Evaluation by $\mathrm{CT}$ angiography. Ann Indian Acad Neurol. 2011;14(4):304-6.

9. Sharma BK, Jain S, Sagar S. Systemic manifestations of Takayasu arteritis: the expanding spectrum. Int J Cardiol. 1996;54:S149.

10. Ashjazadeh N, Shokouhyar S, Ostovan MA. Takayasu arteritis presenting as sudden onset vision loss simulates multiple sclerosis: a case report. J Res Med Sci. 2011;16(1):S442-6.

11. Kerr GS, Hallahan CW, Giordano J, Leavitt RY, Fauci AS, Rottem M, et al. Takayasu arteritis. Ann Intern Med. 1994;120(11):919-29.

12. Soto ME, Espinola N, Flores-Suarez LF, Reyes PA. Takayasu arteritis: clinical features in 110 Mexican Mestizo patients and cardiovascular impact on survival and prognosis. Clin Exp Rheumatol. 2008;26(3 Suppl 49):S9-15.

13. Saab F, Giugliano RP, Giugliano GR. Takayasu Arteritis in a Young Woman: A 4-Year Case History. Tex Heart Inst J. 2009;36(5):470-4.

14. Al-Bishri J. Takayasu's Arteritis: A Review Article. Br J Med Med Res. 2013;3(4):811-20.

15. Alibaz-Öner F, Aydın SZ, Direskeneli H. Recent advances in Takayasu's arteritis. Eur J Rheumatol. 2015;1:24-30.

16. Malik TG, Khalil M, ljaz AU, Bhatti MM. Ocular ischemic syndrome and ischemic optic neuropathy in Takayasu arteritis. J Coll Physicians Surg Pak. 2015;25 Suppl 1:S47-9.

17. Guclu H, Gurlu VP, Ozal SA, Guclu O. Central Retinal Artery Occlusion in Takayasu's Arteritis as the First Presentation of the Disease. Case Rep Ophthalmol Med. 2016;2016:6492513.

18. Peter J, David S, Joseph G, Horo S, Danda D. Hypoperfusive and hypertensive ocular manifestations in Takayasu arteritis. Clin Ophthalmol. 2010;4:1173-6.

19. Peter J, David S, Danda D, Peter JV, Horo S, Joseph G. Ocular manifestations of Takayasu arteritis: a cross-sectional study. Retina. 2011;31(6):1170-8.

20. Koz OG, Ates A, Numan Alp M, Gultan E, Karaaslan Y, Kural G. Bilateral ocular ischemic syndrome as an initial manifestation of Takayasu's arteritis associated with carotid steal syndrome. Rheumatol Int. 2007;27(3):299-302.

\section{Submit your next manuscript to BioMed Central and we will help you at every step:}

- We accept pre-submission inquiries

- Our selector tool helps you to find the most relevant journal

- We provide round the clock customer support

- Convenient online submission

- Thorough peer review

- Inclusion in PubMed and all major indexing services

- Maximum visibility for your research

Submit your manuscript at www.biomedcentral.com/submit

) Biomed Central 